\title{
Endoscopic trans nasal excision of pterygopalatine fossa schwannoma: case report and review of literature
}

\author{
Blessy B. Prabha*, Vijay Rangachari
}

Department of Otorhinolaryngology, Manipal Hospitals, Whitefield, Bengaluru, Karnataka, India

Received: 26 August 2020

Revised: 08 October 2020

Accepted: 13 October 2020

\author{
*Correspondence: \\ Dr. Blessy B. Prabha, \\ E-mail: blessybalaji@gmail.com
}

Copyright: () the author(s), publisher and licensee Medip Academy. This is an open-access article distributed under the terms of the Creative Commons Attribution Non-Commercial License, which permits unrestricted non-commercial use, distribution, and reproduction in any medium, provided the original work is properly cited.

\begin{abstract}
The pterygopalatine fossa is a difficult area for surgical access and lesions in this area traditionally advocated open external trans maxillary approaches. With endoscopic techniques, it is possible to not only access and explore this area but also plan complete excision of lesions in the pterygopalatine fossa. We present a case report of a 26-year-old lady with complaints of pain in the area of the left cheek for 6 months. She had no other co-morbidities. On clinical examination, no abnormality was detected. Radiological examination with magnetic resonance imaging showed a lesion possibly a schwannoma in the left pterygopalatine fossa behind the left maxillary sinus. Complete excision was achieved using trans nasal endoscopic technique through the left maxillary sinus. Histopathological examination confirmed the diagnosis of schwannoma. Post-operative period was uneventful and she was free from any pain and neurological symptoms on subsequent follow up. Schwannomas in the pterygopalatine fossa are rare entities. Endoscopic techniques are safe and effective in accessing the pterygopalatine fossa for excision of lesions situated in this area. This technique obviates the need for external facial incisions or intra oral incisions and helps in good surgical outcomes and quick healing and recovery.
\end{abstract}

Keywords: Pterygopalatine fossa, Schwannomas, Endoscopic excision

\section{INTRODUCTION}

The pterygopalatine fossa (PPF) is a narrow, inverted, cone-shaped space. It is located behind the posterior wall of the maxillary sinus, related with pterygoid plates posteriorly, the greater sphenoid wing and middle cranial fossa superiorly, infratemporal fossa laterally through the pterygomaxillary fissure, the posterior nasal cavity medially through the sphenopalatine foramen, the orbit superiorly through the inferior orbital fissure, and the palate inferiorly through the palatine foramina. ${ }^{1}$ The anteroposterior order of contents is fat, blood vessels and neural structures such as terminal branches of the maxillary artery, pterygopalatine ganglion, vidian nerve and maxillary nerve (V2).
Primary tumors of the PPF, such as meningioma, schwannoma or nasopharyngeal angiofibroma, are rare, most common are sinonasal tumors which frequently extend into the PPF. ${ }^{2} \mathrm{PPF}$ lesions although benign, are challenging to surgeons in terms of access because of their deep location. Achieving surgical clearance is difficult due to their close proximity to various vital structures such as arteries and cranial nerves. ${ }^{3}$ Access to PPF is difficult, conventional methods followed were lateral rhinotomy, midfacial degloving, facial translocation, trans antral maxillectomy, and the Fisch $\mathrm{C}$ and $\mathrm{D}$ procedures. Recent advances such as interventional radiology with preoperative embolization, better understanding of sinus and perisinus anatomy and image guided systems have enabled endoscopic endonasal access to tumors of the PPF. An endoscopic approach to the PPF can overcome most of the disadvantages of open 
techniques with better visualization of these difficult-toaccess locations with decreased morbidity and shorter post-operative recovery periods. ${ }^{1,2}$

\section{CASE REPORT}

A 26-year-old lady presented with complaints of pain in the area of the left cheek since 6 months. There was no history suggestive of sinusitis. She had no other comorbidities. On clinical examination, there was no abnormality detected. There were no signs suggestive of sinusitis. Magnetic resonance imaging (MRI) revealed well defined lesion of around $2.3 \times 2.1 \times 1.4 \mathrm{~cm}$ in the left PPF widening it significantly and centre of the lesion showed intense post-contrast enhancement (Figure 1).
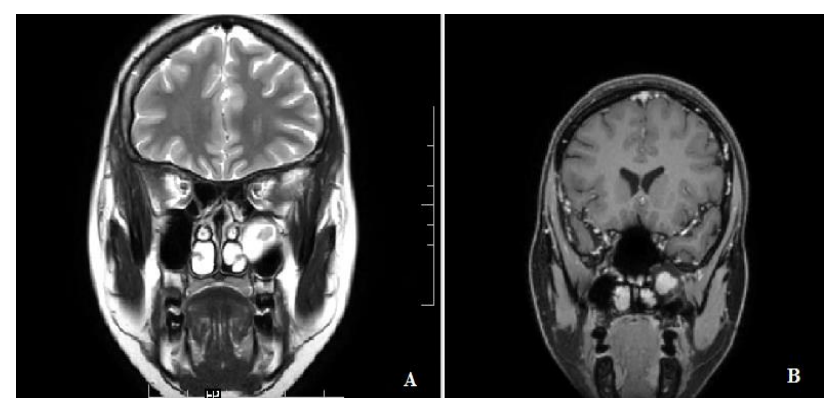

Figure 1: MRI showing (A) well-defined lesion widening the left pterygopalatine fossa $(B)$ intense homogenous enhancement of the centre of the lesion.

Periphery did not show any contrast enhancement. Lesion was seen remodelling the posterior wall of maxillary sinus anteriorly and base of the pterygoid bone posteriorly. There was no extension of lesion into the nasal cavity. Pre-operative CT scan of paranasal sinusess was done to obtain anatomical details and for better surgical planning which revealed the same pathology with otherwise normal sinus anatomy except for the left maxillary sinus area. She underwent endoscopic trans nasal trans maxillary approach to the pterygopalatine fossa. Resection of middle turbinate and inferior turbinate was done with wide middle meatal antrostomy. Removal of inferomedial and posterior wall of maxilla was done for better exposure. Tumour was soft and was separated from the pterygopalatine ganglion by endoscopic fine dissection (Figure 2).

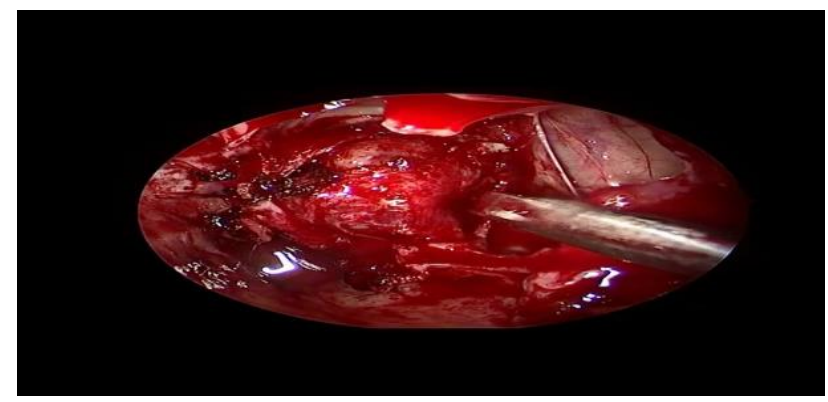

Figure 2: Schwannoma seen in the pterygopalatine fossa behind the left maxillary sinus.

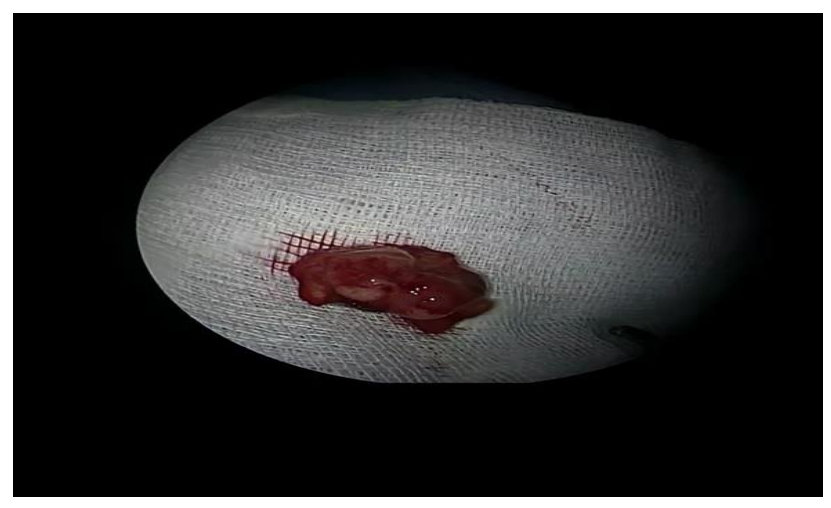

Figure 3: Specimen of excised tumour.

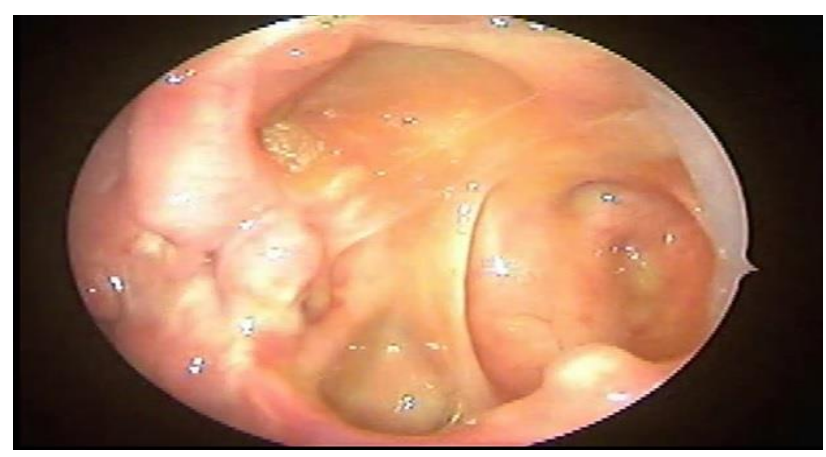

Figure 4: Post-operative nasal endoscopy revealed a healthy well-epithelialised cavity of the left pterygopalatine area.

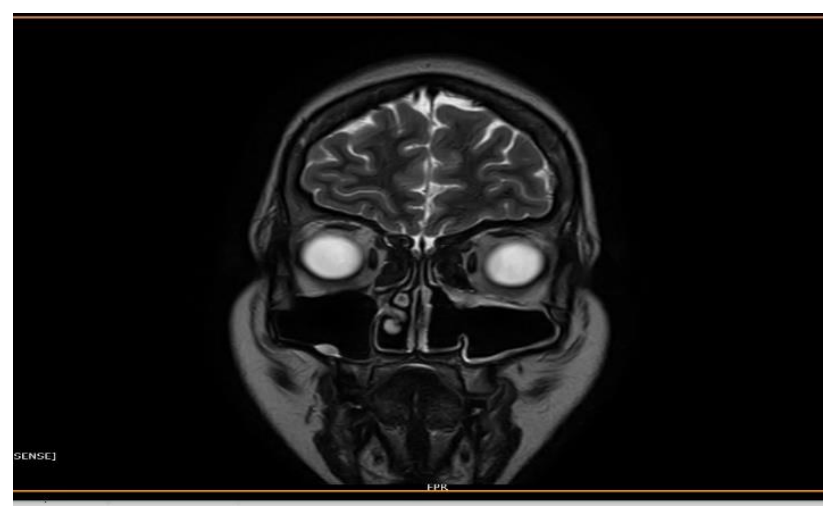

Figure 5: MRI at one-year follow-up showing wide post-operative cavity of left maxillary sinus and pterygopalatine fossa with no residual or recurrent lesion.

Total excision of tumour was done with preservation of neural and vascular structures (Figure 3). The specimen was sent for histopathological examination which revealed a neoplasm formed by wavy spindle cells with hypocellular and hypercellular areas, verrocay bodies were seen and was characteristic of benign schwannoma. Patient had an uneventful post-operative recovery. On subsequent regular weekly follow up, there was no bleeding or epiphora but she had numbness and hypoaesthesia over left half of face for three to four weeks which subsequently recovered. Post-operative 
nasal endoscopy was done at 12 weeks which revealed a healthy well epithelialised sinus cavity (Figure 4).

At follow up of one year, she was asymptomatic and post-operative MRI was done which revealed postoperative changes in widened left maxillary sinus, sphenopalatine foramen and pterygopalatine fossa with signs of bone remodelling and no evidence of residual or recurrent lesion (Figure 5).

\section{DISCUSSION}

Schwannomas or neurilemmomas are benign tumors derived from the Schwann cells of the nerve sheath. Schwann cells are derived from nerve sheath which was first described by Verocay. These tumors are encapsulated, less aggressive locally, lower malignant potential and less association with von Recklinghausen's disease when compared to neurofibromas. These are rare and can be found in any part of the body, around 25-35\% of cases are found at the level of the head and neck and less than four percent of them involve the nasal cavity and paranasal sinuses. The histological aspect of this tumor is differentiated by two main histological patterns the Antoni A (fasciculated) or organized pattern, represented by cells disposed in a "palisade" manner, and the Antoni B (reticular) or disorganized pattern, represented by a looser stroma with myxoid areas and disorganized disposition of cells, which was described by Antoni. These lesions can arise from somatic nerves and autonomic nerves of the nose and paranasal sinuses. Schwannomas are not derived from olfactory and optic nerves as they lack Schwann cells. The most common sites involved are the naso-ethmoidal complex, the maxillary sinus, the nasal cavity, and the sphenoid sinus. The most common presenting features of schwannomas are nasal block, mucopurulent discharge, decreased smell sensation, exophthalmos, and facial swelling, facial pain is more common in tumors of the maxillary sinus and the pterygomaxillary fossa, epistaxis is seen in nasal and ethmoidal tumors, sphenoid sinus lesions can have visual disturbances such as diplopia with involvement of the third, fourth, and sixth cranial nerves, hypopituitarism is seen if the tumor extends posteriorly toward the hypophysis. ${ }^{4}$ Surgery is main stay of treatment for both benign and malignant schwannomas as they are radioresistant. 5,6 The preoperative radiological assessment of the tumor is a crucial guide to management. Dublin et al stated that a CT scan helps to assess the extension of the tumor. MRI helps to know the intracranial extension and differentiate the cause of sinus opacification. ${ }^{7}$ Som et al stated that a bright signal is seen in T2 weighted MRI images of neuromas of the paranasal sinuses with an intermediate T2 signal for the other sino nasal tumors. A profound knowledge of anatomy is essential for performing safe surgery. ${ }^{8}$ The PPF is anatomically more complex because of its contents such as vital neural and vascular structures which are interlinked to the orbit, middle cranial fossa, nasal cavity and oral cavity. ${ }^{2}$ Two major approaches of PPF are the anterior approach through the anterior wall of maxillary sinus by either Weber-Fergusson or sublabial incision and the trans nasal approach through the medial wall of maxillary sinus. ${ }^{3}$ Natural routes through the nasal and paranasal cavities to gain access to PPF reduces morbidity associated with external approach. Alfieri et al explains about the various approaches to expose PPF like the endonasal middle meatal trans palatine approach, the endonasal middle meatal trans antral approach, and the endonasal inferior turbinectomy trans antral approach to expose the PPF in eight cadaveric specimens, and found that the inferior turbinectomy trans antral approach allowed the most accessible surgical space for manipulation. ${ }^{9}$ As these are generally deep seated tumours, the lateral approaches have to encounter the obstruction due to temporal muscles, the vertical segment of the mandible or even the parapharyngeal tissue. ${ }^{3}$ The most comprehensive study for diagnostic and therapeutic approach to PPF tumors has been reported in the literature by Battaglia et al. ${ }^{10}$ They published a case series of 37 patients treated during a 13-year period. To achieve appropriate endoscopic surgical space, to allow safe manipulation and tissue dissection, access to the posterior wall of maxillary sinus was achieved through middle meatal antrostomy. ${ }^{4}$ The other advantages of the endoscopic approach to the skull base tumors include avoidance of external incisions, decreased trauma to soft tissue and bone, fewer complications, reduced risk of neurologic damage, improved postoperative quality of life, and faster recovery time. ${ }^{3,4}$ In endonasal endoscopic approaches to the skull base, the vidian nerve serves as an anatomical landmark for petrous ICA. ${ }^{3}$ Endoscopic endonasal approach has a limiting factor in terms of management of massive blood loss due to vascular complications caused by damage to branches of the maxillary artery. No other major intraoperative complications are encountered generally except for few minor complications such as V2 hyposthesia and trismus. Hence, physiotherapy for postoperative trismus is advised for all surgeries involving PPF. Post-surgical morbidity can be limited by the preservation of the neural structures. The reduced incidence of complications with capability for complete resection makes endoscopic technique suitable, safe and favourable for the management of PPF lesions. ${ }^{2}$

\section{CONCLUSION}

Endoscopic trans nasal approach to PPF Schwannoma provides better access for surgical clearance as they are encapsulated lesions. This technique prevents external scars and cosmetic deformities, results in better healing, reduced morbidity, shorter recovery time and early discharge from hospital. The essential prerequisites needed for such complex surgeries are detailed radiological evaluation, state of the art nasal endoscopes with monitors, good instrumentation, thorough anatomical knowledge and last but not the least, expertise of the surgeon in handling such advanced minimally invasive techniques. It is essential to have a high index of suspicion in patients with atypical facial pain without any 
symptoms suggestive of sinusitis. PPF Schwannoma should be borne in mind as a differential diagnosis in such scenarios.

\section{ACKNOWLEDGEMENTS}

Dr Abha Verma: Consultant Neuroradiologist, Manipal Hospitals Whitefield, Bengaluru, India.

\section{Funding: No funding sources}

Conflict of interest: None declared

Ethical approval: Not required

\section{REFERENCES}

1. DelGaudio JM. Endoscopic transnasal approach to the pterygopalatine fossa. Arch Otolaryngol Head Neck Surg. 2003;129(4):441-6.

2. Plzák J, Kratochvil V, Kešner A, Šurda P, Vlasák A, Zvěřina E. Endoscopic endonasal approach for mass resection of the pterygopalatine fossa. Clinic. 2017;72(9):554-61.

3. Xue Z, Liu J, Bi ZY, Yi ZQ, Bao SD, Liu PN et al, Evolution of transmaxillary approach to tumors in pterygopalatine fossa and infratemporal fossa: anatomic simulation and clinical practice. Chin Med J. 2019;132(7):798.

4. Pasquini E, Sciarretta V, Farneti G, Ippolito A, Mazzatenta D, Frank G. Endoscopic endonasal approach for the treatment of benign schwannoma of the sinonasal tract and pterygopalatine fossa. Am J Rhinol. 2002;16(2):113-8.
5. Robitaille Y, Seemayer TA, El Deiry A. Peripheral nerve tumors involving paranasal sinuses: a case report and review of the literature. Canc. 1975;35(4):1254-8.

6. Perzin KH, Panyu H, Wechter S. Nonepithelial tumors of the nasal cavity, paranasal sinuses and nasopharynx. A clinicopathologic study. XII: Schwann cell tumors (neurilemoma, neurofibroma, malignant schwannoma). Canc. 1982;50(10):2193202.

7. Dublin $\mathrm{AB}$, Dedo $\mathrm{HH}$, Bridger WH. Intranasal schwannoma: magnetic resonance and computed tomography appearance. Am J Otolaryngol. 1995;16(4):251-4.

8. Som PM, Shapiro MD, Biller HF, Sasaki C, Lawson W. Sinonasal tumors and inflammatory tissues: differentiation with MR imaging. Radiol. 1988;167(3):803-8.

9. Alfieri A, Jho HD, Schettino R, Tschabitscher M. Endoscopic endonasal approach to the pterygopalatine fossa: anatomic study. Neurosurg. 2003;52(2):374-80.

10. Battaglia P, Turri-Zanoni M, Lepera D, Sica E, Karligkiotis A, Dallan I et al, Endoscopic transnasal approaches to pterygopalatine fossa tumors. Head Neck. 2016;38(S1):E214-20.

Cite this article as: Prabha BB, Rangachari V. Endoscopic trans nasal excision of pterygopalatine fossa schwannoma: case report and review of literature. Int J Otorhinolaryngol Head Neck Surg 2020;6:2127-30. 